\title{
Perspectivas para a pesquisa e a atuação em geoconservação na Universidade Federal de Santa Maria (UFSM) com foco nas áreas menos desenvolvidas do Brasil meridional
}

\author{
Perspectives to research and acting on geoconservation in the Federal University of \\ Santa Maria (UFSM), focusing on less developed areas of meridional Brazil
}

\author{
André Weissheimer de Borba*1 \\ ${ }^{1}$ Centro de Ciências Naturais e Exatas e Programa de Pós-graduação em Geografia e Geociências, \\ Universidade Federal de Santa Maria, Santa Maria, Brasil
}

\begin{abstract}
Resumo
O presente trabalho aponta perspectivas e possibilidades de pesquisa e extensão em geoconservação, a partir da UFSM, nas mesorregiões da "metade sul gaúcha" e da "grande fronteira do Mercosul", que constituem as áreas menos desenvolvidas do sul do Brasil. As mesorregiões focalizadas possuem aspectos relevantes em termos de geodiversidade e geopatrimônio, bem como problemas socioeconômicos e ambientais que trazem ameaças a sua integridade. Sugerem-se, aqui, objetos de pesquisa em diversas áreas do conhecimento, integração com as universidades recentemente implantadas nessas mesorregiões (UFFS e Unipampa), e ainda possibilidades para aumentar o impacto social do meio acadêmico através de projetos e programas de extensão universitária.
\end{abstract}

Palavras-chave: geopatrimônio, geoconservação, "metade sul gaúcha", "grande fronteira do Mercosul", UFSM.

\begin{abstract}
This paper points out some perspectives and possibilities for research and extension on geoconservation in UFSM, focusing on two underdeveloped regions of southern Brazil: the "southern half" of the Rio Grande do Sul State and the "great Mercosul border", comprising northern Rio Grande do Sul and the western portions of the Santa Catarina and Paraná states. The focused regions possess relevant features of geodiversity and geoheritage, as well as social, economic, and environmental problems that threaten this abiotic part of nature. Research objects in several knowledge areas are suggested here, as well as the necessary integration with universities recently established in those areas (UFFS and Unipampa). Some possibilities for increasing the social impact of the academy, through university extension projects and programs, are also indicated.
\end{abstract}

Keywords: geoheritage, geoconservation, "southern half" of Rio Grande do Sul, "great Mercosul border", UFSM.

* awborba.geo@gmail.com

Recebido: 20/03/2014 Aceito: 20/03/2014 


\section{Introdução}

$\mathrm{O}$ termo 'geoconservação' (Sharples, 2002; Brilha, 2005) designa o conjunto de iniciativas e estratégias destinadas a promover a proteção, valorização, divulgação e uso sustentável dos geomonumentos que melhor representam a evolução geológica de uma região, ou seja, de seu geopatrimônio (revisão de conceitos em Borba, 2011). Ao mesmo tempo, a geoconservação afirma-se cada vez mais como um ramo emergente das geociências (Henriques et al., 2011), com forte integração com outras áreas do conhecimento, especialmente turismo, educação e gestão ambiental.

A geoconservação básica relaciona-se com a elaboração de inventários e avaliações quali-quantitativas do geopatrimônio, por meio das mais variadas metodologias. Enquanto isso, a geoconservação aplicada se refere ao estabelecimento de medidas e ações em três eixos principais: (a) estabelecimento de unidades de conservação da natureza, para proteção dos geomonumentos mais destacados; (b) proposição e oferta de programas de educação geopatrimonial, destinadas a conscientizar a comunidade escolar para a importância de conhecer sua geodiversidade; e (c) implantação de roteiros de geoturismo, um turismo de conhecimento e contato com a natureza, especialmente mediante a interpretação da paisagem e das histórias da evolução geológica.

Estratégias de geoconservação constituem, também, uma nova ferramenta de planejamento territorial e ambiental para municípios, conjuntos de municípios ou mesmo para regiões inteiras, em busca do desenvol- vimento humano e socioeconômico sustentável. Nesse sentido, a universidade possui um papel fundamental na aproximação com o poder público (municipal, estadual), com a iniciativa privada e com o terceiro setor, no sentido de aportar os subsídios técnico-científicos indispensáveis para esse tipo de estratégia. Em muitos casos, o sucesso das iniciativas levam ao reconhecimento de municípios ou associações de municípios como "geoparques" (McKeever \& Zouros, 2005), instituições nas quais a universidade tem igualmente um papel central e decisivo.

Em termos do Brasil meridional, o Ministério da Integração Nacional aponta duas mesorregiões como prioritárias para ações visando à redução das desigualdades (Figura 1): a "metade sul gaúcha", nos domínios do pampa, e a "grande fronteira do Mercosul", a qual engloba o norte/noroeste gaúcho, o oeste catarinense e o sudoeste paranaense. Tais regiões, hoje em dia, contam com universidades públicas federais em fase de consolidação, a Universidade Federal do Pampa (Unipampa) e a Universidade Federal da Fronteira Sul (UFFS), mas ainda são responsáveis por fornecerem - e receberem, depois de formados - grande parte dos estudantes dos cursos da Universidade Federal de Santa Maria (UFSM). A essas mesorregiões, de fantástica geodiversidade e singular geopatrimônio, dedica-se a análise aqui realizada, focalizando as perspectivas para a pesquisa e a atuação em geoconservação, com desejável integração com as instituições citadas, a partir da situação geográfica central da UFSM.

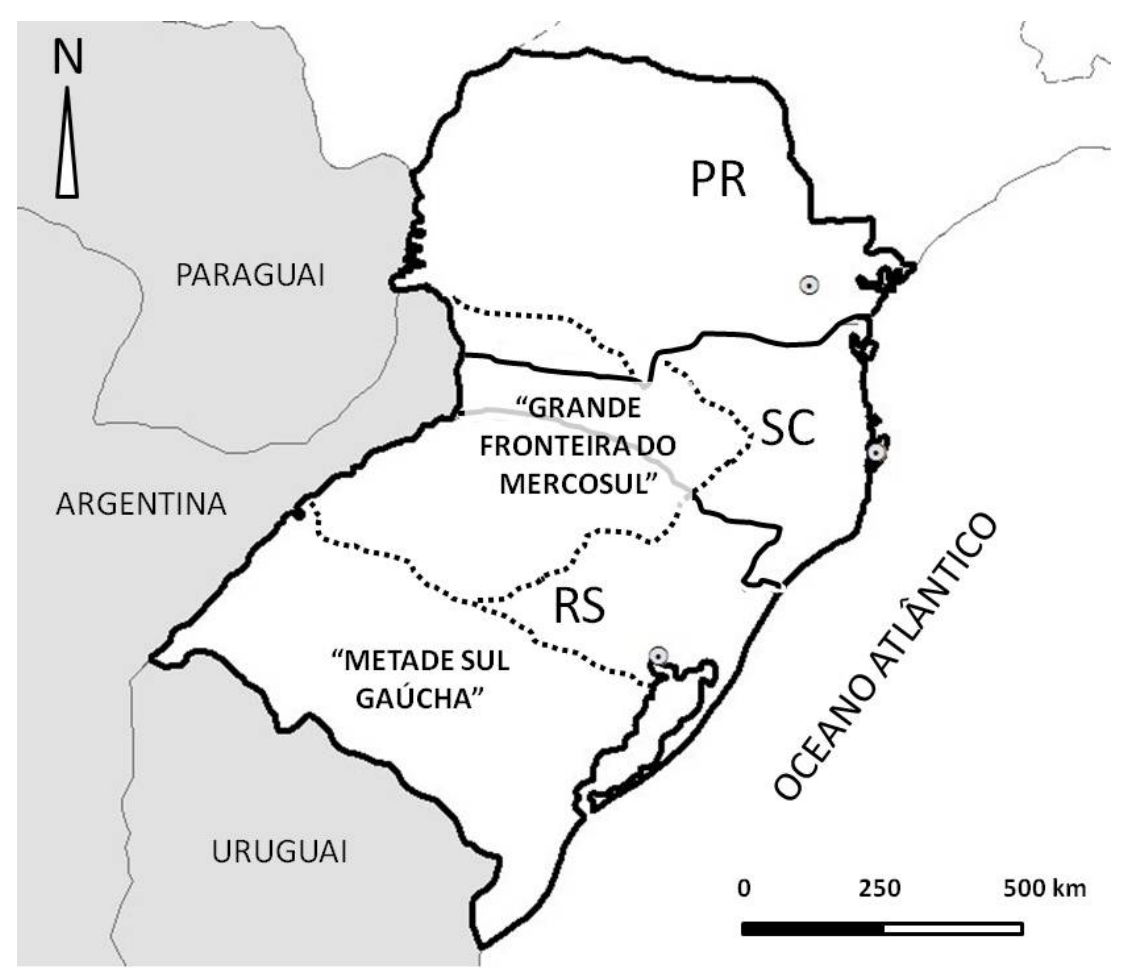

Figura 1 - Mapa esquemático do sul do Brasil, com a abrangência das mesorregiões abordadas neste artigo: a "metade sul gaúcha" e a "grande fronteira do Mercosul". 


\section{Geodiversidade e geopatrimônio das mesorregiões analisadas}

A "metade sul gaúcha" compreende, em termos de geodiversidade, uma série de domínios geológicos distintos, no que diz com a natureza do substrato, sua idade e as formas de relevo e paisagens desenvolvidas a partir dele. O chamado Escudo Sul-rio-grandense, que corresponde na divisão geomorfológica ao Planalto Sul -rio-grandense ou Serras de Sudeste, constitui a região mais diversificada, mas complexa, mais antiga e mais afetada por eventos tectônicos, podendo ser considerado um "hotspot de geodiversidade" (Gray, 2008; Borba, 2011). Ali se encontram rochas de todos os tipos, ígneas (vulcânicas e plutônicas), sedimentares e metamórficas; ali há minerais sulfetados metálicos, gerados por eventos
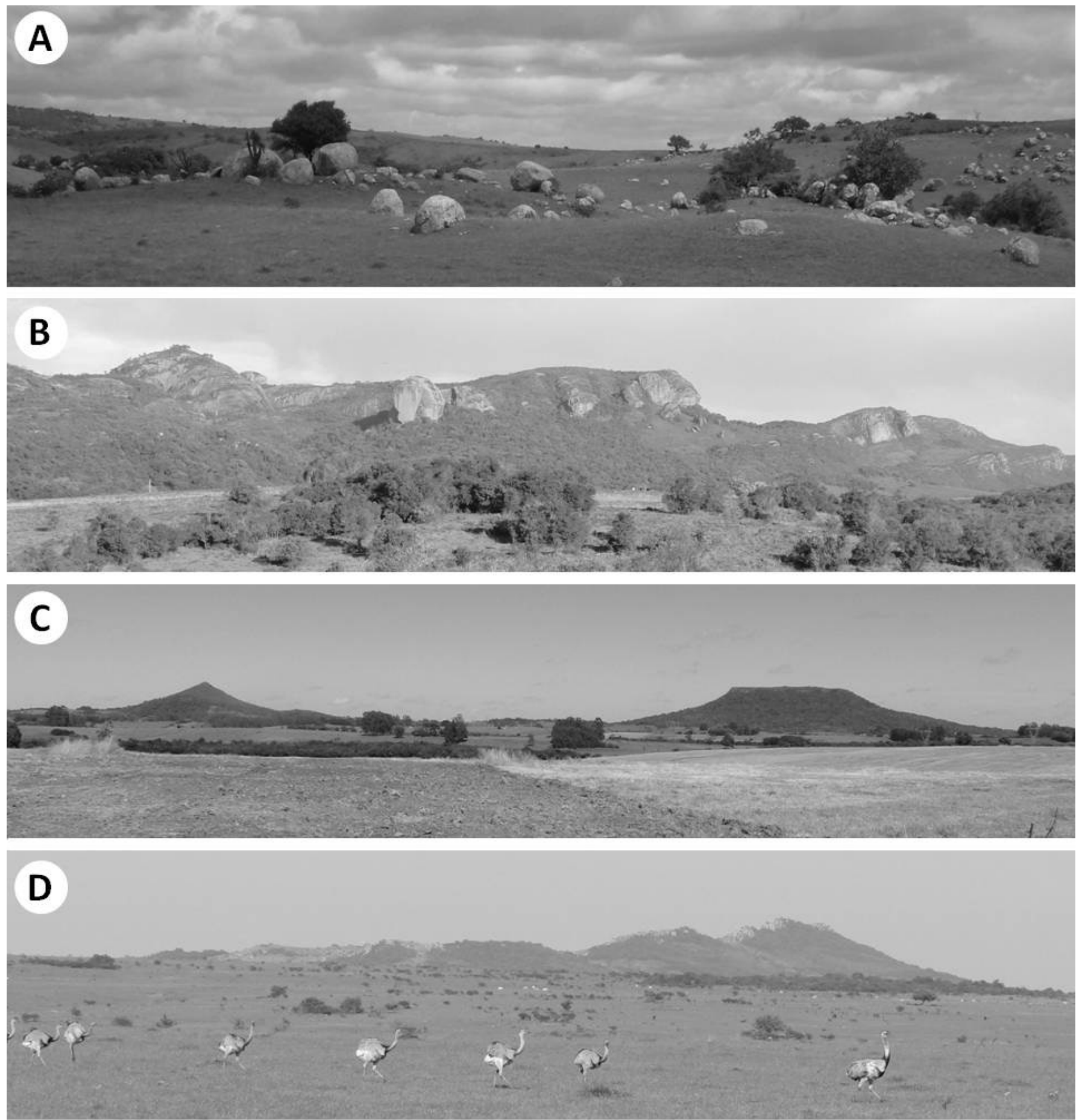

Figura 2 - Geopatrimônio da "metade sul gaúcha": (A) um campo de matacões graníticos próximo à cidade de Herval; (B) a Serra do Segredo, em Caçapava do Sul; (C) os cerros Seio de Moça e Loreto, em São Vicente do Sul; e (D) o Cerro do Jarau, em Quaraí, com emas em primeiro plano (fotos do autor). 
hidrotermais (passagem de fluidos quentes). Nas regiões de Encruzilhada do Sul, Piratini, Pinheiro Machado e Herval, dominam os campos de matacões de granito (Figura 2A), registros das porções profundas de uma antiga cadeia de montanhas. Na região de Caçapava do Sul, "capital gaúcha da geodiversidade" (Borba, 2013) e incomparável sala de aula ao ar livre, impõem-se os cerros de conglomerados e arenitos vermelhos das Pedras das Guaritas, das Minas do Camaquã e da Serra do Segredo (Figura 2B).

Na Depressão Periférica, entre Bagé, Rosário do Sul, São Gabriel e Santa Maria, afloram as rochas sedimentares da Bacia do Paraná, registros de uma evolução "do mar ao deserto" (Holz, 1999). Naquela faixa de altitudes baixas e relevo coxilhado, o geopatrimônio de cunho paleontológico ganha destaque, desde os mesossaurídeos marinhos permianos do Passo de São Borja, em São Gabriel, até os dinossauros triássicos que habitavam as densas florestas de gingkos e coníferas hoje registradas em Mata e São Pedro do Sul (GuerraSommer \& Scherer, 2002). A geomorfologia daquelas áreas (Figura 2C) não é menos interessante: as coxilhas do Batovi ("seio da virgem", na língua dos charruas), a serra do Caverá e os resquícios de - outrora extensos - areais lembram ao estudante - e ao visitante - que os climas já foram mais secos e mais frios (Suertegaray \& Silva, 2009), tendo conformado um relevo com formas singulares. Na Campanha ocidental, já nos domínios do grande rio Uruguai, destacam-se o Cerro do Jarau (Figura 2D), cratera de impacto de meteoro (Phillip et al., 2010) e palco das lendas mais originais da cultura gaúcha, e os solos salinos do Parque Estadual do Espinilho, que abrigam uma fisionomia de savana-parque, única no Rio Grande do Sul.
Já na "grande fronteira do Mercosul", o principal contexto geológico é o do vulcanismo basáltico da Província Paraná, registrado na unidade Serra Geral, um dos mais extensos e volumosos eventos vulcânicos da história do planeta (Hartmann, 2014, neste volume). Nas áreas de Planalto e Ametista do Sul (RS), Entre Rios (SC) e Chopinzinho (PR), os geodos de ametista - uma variedade de quartzo com hábito prismático e cor roxa - contidos em alguns derrames basálticos são considerados gemas de classe mundial, e um geopatrimônio de cunho mineralógico que deve ser valorizado e divulgado. Outro elemento geopatrimonial importante está em subsuperfície ao longo de toda a mesorregião: os arenitos eólicos Botucatu, testemunhos de um grande deserto do Jurássico, e que formam a principal camada do sistema aquífero Guarani, reserva estratégica de água potável. Tais arenitos compõem os blocos construtivos das Missões Jesuíticas (Figura 3A), patrimônio cultural da humanidade e registro histórico de um período e de uma experiência única no mundo. Ainda em termos de recursos hídricos, as fontes e estações de água mineral e termal da região são um atrativo geoturístico relevante. $\mathrm{Na}$ "grande fronteira do Mercosul" encontra-se o Salto do Yucumã (ou Salto del Moconá, para os argentinos), um salto longitudinal (Figura 3B), na mesma direção do fluxo do rio Uruguai, geomonumento atualmente muito ameaçado pela proliferação de barragens e usinas hidrelétricas naquele curso d'água. Por fim, deve-se salientar a presença, na mesorregião, do Domo de Vargeão, outra cratera produzida pelo impacto de um meteoro (Crósta et al., 2005), elemento geopatrimonial situado próximo a grandes cidades como Chapecó, Xanxerê e Concórdia (SC).
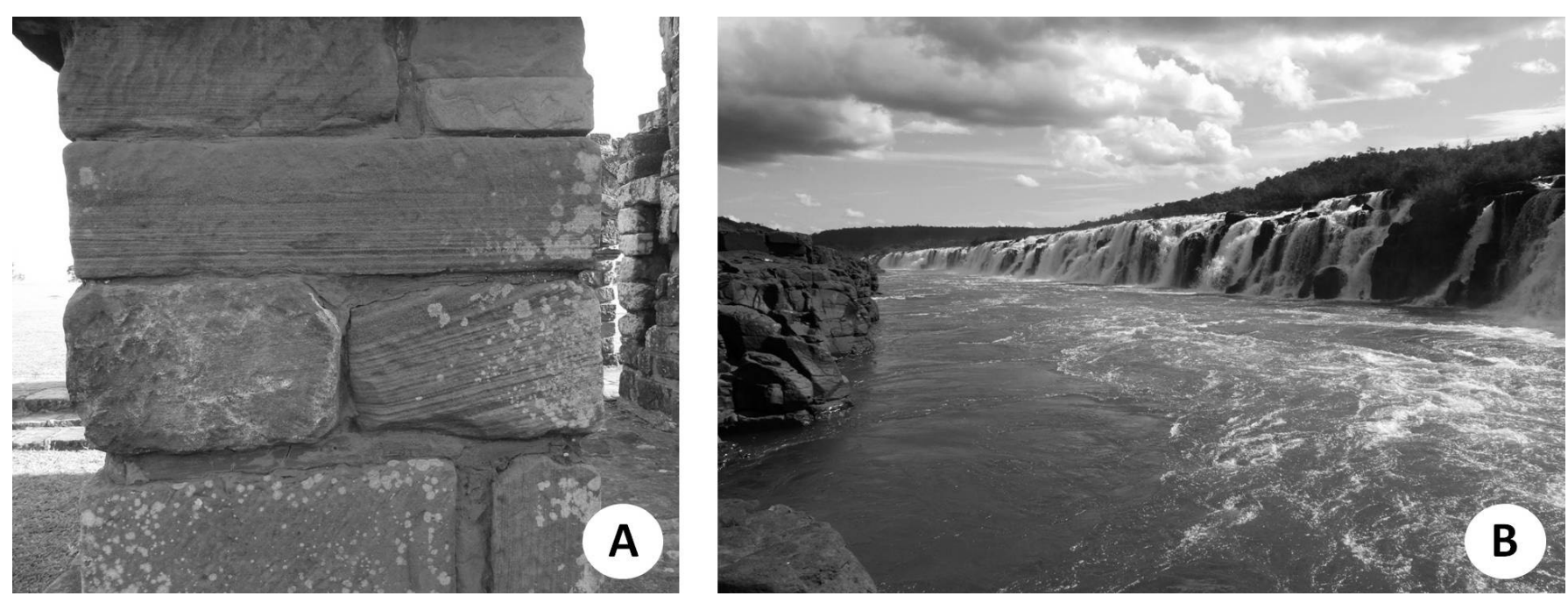

Figura 3 - Dois aspectos geopatrimoniais da "grande fronteira do Mercosul": (A) blocos de arenito eólico, com estratificações cruzadas, que foram utilizados na construção das Missões Jesuíticas; (B) o Salto do Yucumã (ou Moconá), queda d’água longitudinal no rio Uruguai, fronteira Brasil/Argentina 


\section{Pesquisa em geopatrimônio e geoconser- vação}

Com a intenção de apontar perspectivas e possibilidades para a pesquisa em geopatrimônio e geoconservação nessas mesorregiões, inicia-se pelo mais óbvio: a realização de inventários de geomonumentos (geossítios, locais de interesse geológico), em municípios específicos (como aquele realizado por Borba et al., 2013) ou conjuntos de municípios com características e objetivos semelhantes, pode ser objeto de iniciativas da universidade, através de seus pesquisadores e/ou grupos de pesquisa. Da mesma forma, a montagem (design) e o teste de novas metodologias de avaliação quali-quantitativa de geomonumentos, com parâmetros adaptados às realidades regionais e locais, é assunto promissor para o meio acadêmico, especialmente prevendo a utilização de ferramentas de sensoriamento remoto, sistemas de informação geográfica (SIG) e modelos numéricos do terreno (MDT). As metodologias hoje utilizadas (Nascimento et al., 2008; Lima et al., 2010; Fassoulas et al., 2012) são, via de regra, extremamente subjetivas (Borba et al., 2013) e poderiam ganhar muito em credibilidade/aceitação com o acréscimo de ferramentas de SIG e dados concretos.

Um ponto importante a ser investigado, e que foge da atribuição ou mesmo das habilidades dos profissionais da geologia, é a questão das melhores formas de associativismo entre entes públicos e privados para o fim específico da geoconservação. Como integrar as instituições em torno da ideia da proteção e uso sustentável do geopatrimônio? Como sobrepor os limites físicos de municípios, unidades de conservação, comitês de bacias, rotas e regiões turísticas, coordenadorias de educação, entre outros, para alcançar uma geoconservação integral e efetiva? Todos esses questionamentos devem, igualmente, levar em conta os padrões de ocupação do espaço, que são bastante distintos na "metade sul gaúcha" (latifúndio, municípios extensos, grandes distâncias, densidade demográfica baixa) e na "grande fronteira do Mercosul" (ocupação tipo colonial, propriedades de pequeno porte, municípios menores). Ainda nesse aspecto, um ponto fundamental é investigar a contribuição da avaliação geopatrimonial na definição dos limites para novas unidades de conservação (UC), onde essas figuras legais de proteção ao meio ambiente ainda não estejam designadas.

No campo da integração com o turismo (geoturismo), as possibilidades de pesquisa também são interessantes: (a) design de trilhas com conteúdo geopatrimonial, incluindo a capacidade de carga dessas trilhas; (b) definição dos melhores meios de interpretação para cada trilha ou geomonumento particular; (c) adaptação da linguagem geocientífica para que o conteúdo possa ser disponibilizado e compreendido por todos os públicos; (d) integração do geopatrimônio com os aspectos paisagísticos de rodovias e potenciais miradores; entre outras possibilidades. No campo da educação, sugerem-se investigações sobre o perfil dos professores da educação básica em municípios com substancial geopatrimônio, seus conhecimentos prévios sobre geociências, e estudos sobre as melhores maneiras para elaborar oficinas ou minicursos de aperfeiçoamento e qualificação dos professores. Por fim, podem ser montados programas de apresentação das geociências para crianças e jovens (comunidade escolar), mediante definição de conteúdos específicos em geomonumentos selecionados.

\section{Atuação em geoconservação aplicada}

No campo da geoconservação aplicada, muitas iniciativas e atitudes encontram-se dentro do campo de atuação da universidade. De posse dos inventários e avaliações, deve-se buscar uma aproximação com o poder público, especialmente com as prefeituras, pois é no município que se encontram as ferramentas político-administrativas para muitas iniciativas de proteção e de aproveitamento turístico/educativo do geopatrimônio. Ao mesmo tempo, a universidade também pode chamar a atenção do Ministério Público e/ou das instâncias estaduais e até federais de meio ambiente para a importância do estabelecimento de UC para a proteção de geomonumentos que estejam com sua integridade, visibilidade, e/ou mesmo acessibilidade ameaçadas por atividades econômicas danosas (mineração, ocupação irregular, silvicultura de espécies exóticas).

Um caminho a ser considerado é a participação da universidade em instituições ou estruturas (associações, fundações, ONGs, etc.) que se destinem a promover a geoconservação, e mesmo em futuros "geoparques". É muito importante que a universidade contribua com tais iniciativas, apontando caminhos corretos do ponto de vista técnico-científico e ético, ao participar, pelo menos, dos "conselhos científicos" de tais entidades. Inúmeros "geoparques" na Europa e em outras regiões do mundo possuem universidades como parceiras e, em alguns deles, a universidade é, inclusive, responsável pela gestão. Enquanto os "geoparques" não são uma realidade para as mesorregiões em foco, a universidade pode integrar-se também aos demais atores da sociedade para a implantação e o aporte do conteúdo técnico de trilhas e painéis interpretativos em geomonumentos estratégicos. Estabelecer canais de comunicação com a imprensa, especialmente para o esclarecimento das comunidades locais, também é uma iniciativa imprescindível.

Por fim, a educação geopatrimonial deve ser um foco prioritário, considerando os baixos índices de desenvolvimento humano e os fracos resultados da educação - especialmente em ciências - em grande parte dos municípios das duas mesorregiões. A extensão universitária em geoconservação deve atingir os professores da rede pública de educação básica, através de palestras, oficinas e minicursos voltados aos assuntos "geodiversidade e geopatrimônio", para sua qualificação e aperfeiçoa- 
mento. Especialmente nos municípios portadores de geomonumentos de grande valor educativo, a utilização de exemplos locais para conceitos e processos do campo das ciências da natureza (ciências, geografia, biologia) poderá despertar nas crianças e jovens, ao mesmo tempo, curiosidade e orgulho pelo que a natureza produziu e deixou como herança em seu município, em sua região.

\section{Considerações finais}

As possibilidades de pesquisa e extensão universitária, com foco na geoconservação, destinadas às mesorregiões "metade sul gaúcha" e "grande fronteira do Mercosul", a partir da posição central da Universidade Federal de Santa Maria (UFSM) e com recomendável integração às universidades regionais (nomeadamente UFFS e Unipampa), são inúmeras e promissoras. Inventários e avaliações geopatrimoniais, metodologias de quantificação novas e adaptadas às realidades regionais, além de modelos de planejamento, gestão e integração de instituições para a geoconservação, são apenas algumas das perspectivas de pesquisa científica aqui apontadas. No campo da extensão universitária, a educação de crianças e jovens para a valorização do geopatrimônio é um caminho prioritário, na busca de um futuro melhor para essas mesorregiões: um futuro de orgulho, desenvolvimento humano, melhores condições socioeconômicas e preservação do meio ambiente.

\section{Agradecimentos}

Agradeço pelo apoio recebido dos colegas Eliane Foleto, Adriano Figueiró, Átila Da Rosa, Cássio Wollmann e Romário Trentin na idealização de um grupo de pesquisa dedicado à geoconservação no âmbito da Universidade Federal de Santa Maria (UFSM). Agradeço também à colega Jaciele Sell, da Universidade Federal da Fronteira Sul (UFFS), por ter-me apresentado a abrangência das mesorregiões analisadas e destacadas neste trabalho. Por fim, agradeço ao Editor-chefe da Ciência e Natura, Marcelo Barcelos da Rosa, pela oportunidade de integrar a presente edição comemorativa de 35 anos deste periódico.

\section{Referências}

Borba A.W. 2011. Geodiversidade e geopatrimônio como bases para estratégias de geoconservação: conceitos, abordagens, métodos de avaliação e aplicabilidade no contexto do Estado do Rio Grande do Sul. Pesquisas em Geociências, 38 (1): 3-13.
Borba A.W. 2013. Geoconservação em Caçapava do Sul (Escudo Sul-rio-grandense, RS, Brasil): ideias e sugestões com base em avaliação geopatrimonial. In: VIII Simpósio Sul-brasileiro de Geologia, Resumos, Porto Alegre.

Borba A.W., Souza L.F., Mizusaki A.M.P., Almeida D.P.M. \& Stumpf P.P. 2013. Inventário e avaliação quantitativa de geossítios: exemplo de aplicação ao patrimônio geológico do município de Caçapava do Sul (RS, Brasil). Pesquisas em Geociências, 40(3): 275-294.

Brilha, J.B.R. 2005. Património geológico e geoconservação. Palimage Editores, Viseu, 190p.

Crósta A.P., Kazzuo-Vieira C., Choudhouri A., Schrank A. 2005. Astroblema Domo de Vargeão, SC: registro de impacto meteorítico sobre rochas vulcânicas da Bacia do Paraná. In: Winge M., Schobbenhaus C., Berbert-Born M., Queiroz E.T. \& Campos D.A (Eds.) Sítios geológicos e paleontológicos do Brasil - SIGEP (disponível em http://sigep.cprm.gov.br/sitio114/sitio114.pdf, acessado em 03/01/2014).

Fassoulas C., Mouriki D., Dimitriou-Nikolakis P., Iliopoulos G. 2012. Quantitative assessment of geotopes as an effective tool for geoheritage management. Geoheritage, 4(3): 177-193.

Gray M. 2008. Geodiversity: developing the paradigm. Proceedings of the Geologists' Association, 119: 287-298.

Guerra-Sommer M. \& Scherer C.M.S. 2002. Sítios paleobotânicos do Arenito Mata (Mata e São Pedro do Sul), RS: uma das mais importantes 'florestas petrificadas' do planeta. In: Schobbenhaus C., Campos D.A. Queiroz E.T., Winge M. \& BerbertBorn M. (Eds.) Sítios geológicos e paleontológicos do Brasil - SIGEP (disponível em http://sigep. cprm.gov.br/sitio009/sitio009.pdf, acessado em 03/01/2014).

Hartmann L.A. 2014. A história natural do Grupo Serra Geral desde o Cretáceo até o Recente. Ciência e Natura (nesta edição comemorativa).

Henriques M.H., Pena dos Reis R., Brilha J.B.R., Mota T. 2011. Geoconservation as an emerging geoscience. Geoheritage, DOI 10.1007/s12371-0110039-8, publicado on-line em 21/4/2011.

Holz M. 1999. Do mar ao deserto. Editora da UFRGS, Porto Alegre, $142 \mathrm{p}$. 
Lima F.F., Brilha J.B.R., Salamuni E. 2010.

Inventorying geological heritage in large territories: a methodological proposal applied to Brazil.

Geoheritage, 2: 91-99.

McKeever P.J., Zouros N. 2005. Geoparks: celebrating Earth heritage, sustaining local communities.

Episodes, 28(4): 274-278.

Nascimento M.A.L. 2008. Geodiversidade, geoconservação, geoturismo: trinômio importante para a proteção do patrimônio geológico. UFRN, Universidade Federal do Rio Grande do Norte, 84 p.

Phillip R.P., Rolim S.B.A., Sommer C.A., Souza Filho C.R., Lisbôa, N.A. 2010. A estrutura de impacto do Cerro do Jarau, Quaraí, RS. Revista Brasileira de Geociências, 40(4): 468-483.

Sharples C. 2002. Concepts and principles of geoconservation. Tasmanian Parks and Wildlife Service, electronic publication, $81 \mathrm{p}$.

Suertegaray D.M.A., Silva L.A.P. 2009. Tchê Pampa: histórias da natureza gaúcha. In: Pillar V.P., Müller S.C., Castilhos Z.M.S., Jacques A.V.A. (Eds.)

Campos Sulinos: conservação e uso sustentável da biodiversidade. MMA, Brasília, DF, Cap. 3, pp. 42-59. 